\title{
COMPARING EFL LEARNERS' RESPONSES IN ONLINE AND TRADITIONAL CLASSES: A MIXED METHOD APPROACH
}

\author{
Marjan BANAFSHI \\ ORCID: 0000-0002-8825-0359 \\ Faculty of Humanities \\ Payame Noor University \\ Tehran, IRAN
}

Dr. Farzaneh KHODABANDEH

ORCID: 0000-0003-2104-622X

Faculty of Humanities

Payame Noor University

Tehran, IRAN

Dr. Fatemeh HEMMATI

ORCID: 0000-0002-1237-5075

Faculty of Humanities

Payame Noor University

Tehran, IRAN

Received: 25/04/2019 Accepted: 16/09/2019

\begin{abstract}
The aim of this article was twofold. First, it considered the effect of social networks (Telegram) on the vocabulary knowledge of the participants, then it compared the participants' responses in IRF (initiation, response, \& feedback) pattern in two different settings (traditional class and the online one). A group of foreign language learners took the Nelson Proficiency Test and a total of 60 learners were selected to participate in the study. Then they were randomly assigned to an experimental and a control group. After the treatment, the pre-test and post-test results were compared. For the second part of the study, the participants' comments were analyzed quantitatively and qualitatively. The results revealed a significant difference between the two groups, not only in their vocabulary knowledge but also in the way they communicated. This study has implications for both teachers and learners to increase their awareness of the benefits of new opportunities provided by technology in teaching-learning process.
\end{abstract}

Keywords: Discourse analysis, IRF, online setting, students' response, traditional setting.

\section{INTRODUCTION}

Tremendous growth of social networks has had a high impact on the development of the students' learning and social lives (Rithika \& Selvaraj, 2013). Social networks have long been used for educational purposes and researchers argue that students are more interested in online environment than traditional setting for learning different skills (Khodabandeh, 2018; Miyazoe \& Anderson, 2010). Some researchers believe that online setting is more helpful for learners than traditional one (Khodabandeh, Alian \& Soleimani, 2017). Wang (2014) argued that online websites such as Wikis are more useful than traditional classrooms; because they increase students' motivation for learning. In social networks and online environment, students can interact with each other which enhances their learning and their participation (Karayan \& Crowe, 1997; Smith \& Hardaker, 2000). 
The interaction of teachers and students in classrooms should be taken into account very seriously (Mishler, 1975). According to Liu and Le (2012) "Interaction is very important not only for teachers' classroom organization but also for students' language learning” (p.1), so it should be investigated (Allwrigh \& Bailey, 1991; Allwright, 1980; Tsui, 1995; Liu \& Le, 2012; Smith \& Higginsb, 2006). It is a fact that interaction with peers facilitates learning. As a matter of fact, social interaction helps people learn more than individual learning (Vygotsky, 1978).

Understanding the patterns of the interactions is very important and has long been under investigation by researchers. For example, Sinclair and Coulthard (1975) stated that classroom discourse is mostly made of three moves; teacher initiation (I), student response (R) and teacher feedback/comment (F) of the student's response (IRF). According to Wells (1999), a great amount of classroom interaction is made up of these three moves (about 70\%).

Online interaction is popular in social networks especially Telegram which is a fast and free messaging application. Telegram is a very useful context for learning because it provides motivation and excitement for learners (Badri, 2015). Social networking sites are educational tools because learners can use them to communicate with their peers and share their knowledge (Lee \& McLoughlin as cited in Stanciu, Mihai, \& Aleca,2012, p.57). Students' interaction in online classes is very different from face-to-face ones (Kearsley, 2000). According to McConnell (2000), the instructor's control is not very much in online classes but learners participate equally in such classes. On the contrary, in face to face classes, the instructor controls most of the conversations of the students. In any case, understanding the patterns of these interactions is very important in both online and traditional classes and have long been under investigation by researchers (Heidari, Khodabandeh \& Soleimani, 2018). In order to expand on previous research, this study investigates English foreign language (EFL) learners' interactions in two different contexts of learning (Telegram and traditional classes). Besides, this study is going to compare two different modes of learning vocabulary and to see which group (traditional or Telegram group) perform better in learning new words. Thus, this research is intended to fill the research gap and to examine the following questions:

Q1: Does teaching through social networks have any effect on EFL learners' vocabulary knowledge?

Q2: What are the features of the participants' comments in the virtual classes?

\section{LITERATURE REVIEW}

\section{IRF}

It is believed that teachers control the interaction in IRF pattern (Sinclair \& Coulthard 1975, Cazden 2001). Markee (2000) believes that "teachers maintain control over the moment-by moment content and direction of classroom talk by reserving the right to ask questions. Students are thereby sequentially obligated to respond with answers." (p.71). Some researchers believe that this pattern provides opportunities for both teachers and their students to take turns in the interaction (Nassaji \& Wells 2000). For example, the first part of the IRF is not always occupied by the teacher. In some situations, students start this structural pattern. They can obtain the last part that is F, too (Sunderland, 2001). Sometimes, teachers or students deviate from the IRF pattern (Candela 1999; Thornborrow 2002).

Van Lier (1996) states that IRF pattern restricts students and do not allow them to express themselves freely. He further talks about the advantages of the IRF pattern in learning foreign languages because he thinks that this regular pattern does not allow the discourse to be deviated from the main theme (here teaching foreign language) and since the teacher controls the class interactions, so learning will be improved. Rampton (2002) argues that when teachers control the classroom, students' motivation to participate will be decreased. The use of IRF patter decreases the students' motivation by assigning the teacher as the authority in the class (Van Lier,1996). 


\section{Online Interaction}

Classroom discourse and interaction have been investigated by researchers for many years because understanding the nature of this interaction can affect learning (Cullen, 1998; Rymes,2009; Walsh, 2006). Song and McNary (2011) investigated the students' online communication with the focus on their posts that they launched in online setting. Results of the study showed that the students' posts were different. They posted various kinds of posts such as suggestions, acknowledgement, argument, request and so on. They concluded that the number of posts does not have any impact on the students' advancement. When students take part in online interaction, they can look at others' posts which is an opportunity afforded by online technologies (Gallini \& Barron, 2002).

Some researchers examined the number of students' posts in online settings and its relationship with students' progress and they found different results. While some of them believe that the number does have effect on students' success (Kay, 2006; Ramos \& Yudko, 2008) others think it does not have any effect on students' grades and their performance (Song \& McNary, 2011). Aydin (2014) investigated the EFL learners' interactions with their teachers on Facebook and found out that age, gender and the number of training years affect their behavior in interaction with their teacher. Zeng and Shigenobu (2009) investigated the EFL learners in computer-mediated interaction. They found that the students' language ability improved with cooperation with each other.

\section{Social Networking Sites}

Using mobile technology and social networks have become part of the life of most students all around the world and it has had an impact on the process of their learning (Wanger \&Wilson, 2005). Language learning through social networks has been studied by researchers (e.g. Firat \& Serpil, 2017; Khabiri \& Khatibi, 2013; Yousefzadeh, 2012). Greenhow (2011) said that social networking sites support learning and new technologies are very useful for educational goals. In a study conducted by Shabani, Parseh and Gerdabi (2014), using chat in online setting and its impact on vocabulary learning was examined. They found that the group which learnt vocabulary by using chat showed better performance than the group who did not use it. Similarly, Kolokytha, Loutrouki,Valsamidi, and Florou (2015) confirmed that social networks can be used as a learning tool and they provide an environment for discussion outside of the classroom. Doing assignments and sharing them in virtual networks motivate students to do them and get better results (Alian, Khodabandeh \& Soleimani, 2017). In line with previous researchers, Heidari, Khodabandeh and Soleimani (2018) confirmed that teaching through social networks especially Telegram provides new opportunities for teaching-learning process because students are eager to communicate within the virtual environments. Teaching through social networks makes learning more interesting for students because it allows them to interact with each other and their teacher more than the participants of the face-to-face classes (Naseri \& khodabandeh, 2019).

\section{The Keyword Method}

Taking into account the importance of vocabulary knowledge in learning a foreign language, teachers have always tried to find a way to facilitate acquiring it (Kilickaya \& Krajka, 2010). One of the best strategies which can enhance learning is using the keyword method which is very popular these days and it is the verbal linkage with visual imagery in the memory process (Rodriguez \& Sadoski, 2000). This method was first presented by Atkinson (1975) and his colleagues (Atkinson \& Raugh,1975), and has two stages; first, one should find a word (maybe in one's mother tongue) which is acoustically similar to the target word. This word is called the "keyword." Next, to recall the word better, a picture is presented (Hell \& Mahn, 1997). The effectiveness of the keyword method has been proved in many studies (e.g., Atkinson, 1975; Shapiro \& Waters ,2005; Wyra, Lawson, \& Hongi, 2007; Rodriguez \& Sadoski, 2000; Sagarra \& Alba,2006). Avila and Sadoski (1996) say that the keyword method is one of the most effective methods for remembering 
words that increase delayed and immediate recall as well. This method is very popular because it is not only useful in foreign language and vocabulary learning but also in social studies and science (Berkeley, Mastropieri, Marshak, \& Scruggs, 2010). Taking into account the effectiveness of social networks and the keyword method in vocabulary learning, this study has combined these two powerful instruments, that is using the keyword method in online classes which has not been done in previous studies to examine if the method is effective in this setting too. As it can be seen, analyzing students' responses in the IRF pattern has not been investigated so far. This study investigates the using keyword method in Telegram, as well. The effectiveness of teaching vocabulary in Telegram through the keyword method has not been investigated by other researchers, too.

\section{METHODOLOGY}

\section{Participants}

Sixty Iranian Payame Noor University (PNU) students majored in English translation course who were in intermediate level were selected as the samples of this study based on a proficiency test. Then, they were randomly assigned to an experimental and a control group. The participants were both female (30) and male (30) EFL learners and their age ranged between 18-and 22.

\section{Data Collection}

In order to collect enough data for this study, a vocabulary learning course was designed. In the traditional classroom the interaction and the dialogues between the teacher and the participants were recorded by a video camera. The interaction in Telegram was through text, so the learners' responses and teacher's questions and all of the interactions remained on the screen for further analysis. The dataset of this study was all students' answers and comments.

\section{Instrumentation}

Nelson Test of Proficiency (350A)

This test was used to homogenize the subjects regarding their proficiency level. The test was administered to a group of intermediate learners in Mobarake Payame Noor university to select participants. Those participants (60) whose means were one standard deviation above and below the mean were selected as samples.

\section{Pre-test and Post-test}

The participants in both groups took a pre-test (multiple choice items based on vocabulary). It was developed by the researcher and had 40 items. The vocabulary tests which were in the pretest and the posttest were chosen from a book named "504 Absolutely Essential Words". The participants' achievement during the course was tested using a post-test ( 40 multiple choice developed by the researcher). Like the pretest, the items were selected from the same book.

\section{The Validity}

The researcher made tests with the help of another colleague. To be sure about the validity of the tests, a kind of criterion- related validity called concurrent validity was used. These tests and the Nelson test were administered to EFL learners and then correlation between scores obtained on the vocabulary test and the vocabulary section of the Nelson proficiency test were computed. Determining the inter-rater reliability of coding the students' responses was done with the assistance of another rater, who was an EFL instructor, and the interrater reliability was computed through the Pearson's correlation coefficient test. Estimating reliability of the test was done through Cronbach's formula of reliability. The reliability estimate for the test turned out to be 0.77 . 


\section{Procedure}

After dividing the groups and taking a pre-test from the participants, the experimental group received instruction through Telegram. The participants of the experimental group checked their cell phones in a special time during the week ( 3 days a week) and took part in the online class. For this study, 30 new words based on the book entitled "504 Absolutely Essential Words" were taught. These words were sent to the participants in the experimental group. This process continued for one term (12 sessions, 3 days a week, about one month). The control group learned the same vocabularies in the classroom. New vocabulary items were written on the board and then the printed pictures like the ones in the Telegram group were given to the participants. New vocabularies were presented with pictures like figure 1.

For example, for the word 'shriek', the above picture was given to the participants to help them remember it better. Because according to the keyword method, the word 'shriek' is acoustically like 'Shrek' (the green giant) who is screaming. And the meaning of 'shriek' is to scream. In the traditional group, the printed pictures were presented. At the end of the treatment, the participants in both groups took the posttest. Finally, the results of both the pretest and the posttest were compared.

Regarding the second question of the research, the classroom interaction among the participates was recorded

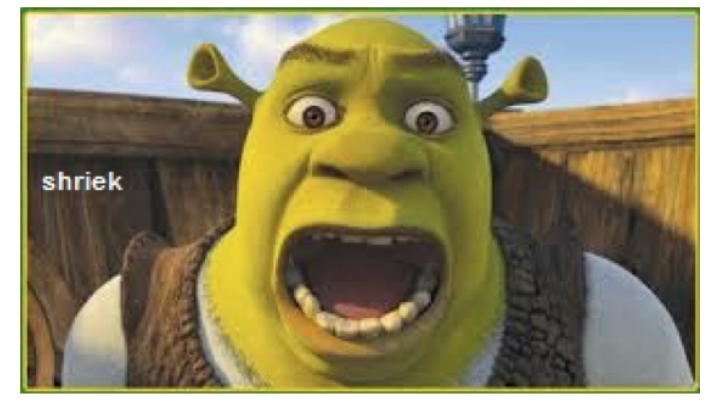

Figure 1. New vocabulary presentation and analyzed. In the traditional classroom, the interaction was video-taped (each class lasted about one hour). Because of avoiding the halo effect, this part of the study was revealed to the participants. The interaction in Telegram was through text, so the participants' responses and the teacher's questions and all of the interactions remained on the screen which were saved in Telegram Chat History for further analysis. Three kinds of exchanges were analyzed in this study; R (TS) pattern refers to the exchange that comprises of only one initiating move from the instructor and a responding move from a student. In R (ST), it is the student who makes the initiation and the teacher offers a responding move. Moreover, in R (SS), it is the student who makes the initiation and he/she offers the answer him/herself.

\section{RESULTS}

\section{Overview}

In this part, the participants' performances on pre- and post-tests are first compared within each group and then between two ones. Moreover, the analysis of the participants' responses within the two groups are presented.

\section{Data Analysis}

In order to examine the research questions addressed in the research, the following statistical procedures were conducted: (1) Calculation of the average number of the participants' responses, (2) Shapiro-Wilk test, (3) Q-Q plot, (4) descriptive statistics, (5) Wilcoxon test, and (6) Mann-Whitney U test.

Firstly, the raw data taken from the pre- and post-tests were examined for the assumption of normal distribution via Shapiro-Wilk statistical test and Q-Q plots. Secondly, descriptive statistics were applied to determine the mean score $(M)$ and standard deviation $(S D)$ for the data on pre- and post-tests. Thirdly, Wilcoxon test was applied to examine the differences within the pre- and post-tests in each of the groups. Then, Mann-Whitney $\mathrm{U}$ test was used to examine between-group differences in the pre- and post-tests. Finally, the mean number of the responses presented by the participants of the two groups were calculated and examined to see if there were any significant differences between them through independent samples t-test. 


\section{Comparing Pre- and Post-tests of the Traditional Group}

To compare the pre- and post-tests of the participants of the traditional group, the raw data taken from the related tests were first examined for the assumption of normal distribution. The results were as follows:

Table 1. The Analysis of Pre- and Post-Tests of the Traditional Classroom, Test of Normality

\begin{tabular}{lccc}
\hline \multirow{2}{*}{ Traditional classroom } & \multicolumn{3}{c}{ Shapiro-Wilk } \\
\cline { 2 - 4 } & Statistic & $\mathrm{df}$ & Sig. \\
\hline pre-tests & .868 & 30 & .002 \\
post-tests & .960 & 30 & .312 \\
\hline \hline
\end{tabular}

Note. The alpha level for the analysis was set at .05 for test of significance.

Since the observed values for pre-test data $(\mathrm{p}=.02)$ and post-test data $(\mathrm{p}=.01)$ in the traditional group are less than the critical value at .05 level of significance, these data do not meet the normality assumption.

A check as to whether or not we can assume a normal distribution can be made by drawing a probability plot. The data of pre- and post-tests of the traditional group are compared with the expected scores of the model, in this case a normal distribution. If a normal distribution is the appropriate model, the data will lie approximately on a straight line through the origin. The probability plots for the data of pre- and post-tests have been shown in Tables 1 and 2. The Tables show that a normal distribution cannot be assumed for these data in pre- and post-tests. Table 2 presents the descriptive statistics for pre- and post-tests of the traditional group.

Table 2. The Analysis of Pre- and Post-Tests of the Traditional Classroom, Descriptive Statistics

\begin{tabular}{cccc}
\hline Traditional classroom & N & Mean & Std. Deviation \\
\hline pre-tests & 30 & 12.73 & 5.04 \\
post-tests & 30 & 20.80 & 5.59 \\
\hline
\end{tabular}

In order to find out if there was any significant difference between pre- and post-tests of the traditional classroom, the participants' performances on pre- and post-tests were compared. In doing so, Wilcoxon Signed Rank Test was employed to investigate the observable variation in the participants performances. The results were as follows:

Table 3. The Analysis of Pre- and Post-Tests of the Traditional Classroom, Wilcoxon Signed Rank Test

\begin{tabular}{cc}
\hline Traditional classroom & pre- and post-tests \\
\hline $\mathrm{Z}$ & -4.150 \\
Asymp. Sig. (2-tailed) & .000 \\
\hline \hline
\end{tabular}

Note. The alpha level for the analysis was set at 0.05 for test of significance.

Table 3 shows that the probability level of pre- and post-tests is . 05 , which is equal to the significance level of .05. Statistically, it follows that there is a significant difference between pre- and post-tests of the traditional group. 


\section{Comparing Pre- and Post-tests of the Online Classroom}

To compare the pre- and post-tests of the subjects of the online classroom, the raw data taken from the related tests were first examined for the assumption of normal distribution. The results were as follows:

Table 4. The Analysis of Pre- and Post-Tests of the Online Classroom, Test of Normality

\begin{tabular}{ccccc}
\hline \multirow{2}{*}{ Online classroom } & \multicolumn{3}{c}{ Shapiro-Wilk } \\
\cline { 2 - 5 } & Statistic & df & Sig. \\
\hline pre-tests & .929 & 30 & .047 \\
post-tests & .827 & 30 & .000 \\
\hline
\end{tabular}

Note. The alpha level for the analysis was set at .05 for test of significance.

Applying normality analysis, it was revealed that the data on pre- and post-tests of the online group didn't follow normality assumptions. The observed values of pre- and post-tests obtained by Shapiro-Wilk are .01 and .00 which are less than critical value at .05 level of significance and it proved that the distributions were not normal, as it can be seen in Table 4 .

The Tables 3 and 4 show that a normal distribution cannot be assumed for the data on both pre- and posttests of the online group. Table 5 presents the descriptive statistics for pre- and post-tests of the online group.

Table 5. The Analysis of Pre- and Post-Tests of the Online Classroom, Descriptive Statistics

\begin{tabular}{cccc}
\hline Online classroom & N & Mean & Std. Deviation \\
\hline pre-tests & 30 & 14.06 & 4.24 \\
post-tests & 30 & 26.60 & 3.85 \\
\hline
\end{tabular}

Also, Wilcoxon Signed Rank Test was employed to investigate the observable variation in the participants' performances. The results were as follows:

Table 6. The Analysis of Pre- and Post-Tests of the Online Classroom, Wilcoxon Signed Rank Test

\begin{tabular}{cc}
\hline Online classroom & pre- and post-tests \\
\hline$Z$ & -4.787 \\
Asymp. Sig. (2-tailed) & .000 \\
\hline
\end{tabular}

Note. The alpha level for the analysis was set at 0.05 for test of significance.

Table 6 shows that the probability level of pre- and post-tests is .00, which is less than the significance level of .05. Statistically, it follows that there is a significant difference between pre- and post-tests of the online group.

\section{Comparing Pre-tests of the Traditional Group and the Online Group}

To compare the pre-tests of the participants of the traditional classroom and the online classroom, the raw data taken from the related tests were first examined for the assumption of normal distribution. The results were as follows: 
Table 7. The Analysis of Pre-Tests of the Traditional Classroom and the Online Classroom, Test of Normality

\begin{tabular}{llll}
\hline \multirow{2}{*}{ pre-tests } & \multicolumn{3}{c}{ Shapiro -Wilk } \\
\cline { 2 - 4 } & Statistic & $\mathrm{df}$ & Sig. \\
\hline Traditional classroom & .868 & 30 & .002 \\
Online classroom & .929 & 30 & .047 \\
\hline
\end{tabular}

Note. The alpha level for the analysis was set at .05 for test of significance.

Applying normality analysis, it was revealed that the data on pre-tests of the traditional group and the online one didn't follow normality assumptions. The observed values of pre-tests obtained by Shapiro-Wilk are .02 and .01 which are less than critical value at .05 level of significance and it proved that the distributions were not normal, as it can be seen in Table 7.

The probability plots for the data on pre-tests of the two groups are shown in Tables 5 and 6 . The Tables show that a normal distribution cannot be assumed for these data on pre-tests. Table 8 presents the descriptive statistics for pre-tests of the traditional group and the online one.

Table 8. The Analysis of Pre-Tests of the Traditional Classroom and the Online Classroom, Descriptive Statistics

\begin{tabular}{cccc}
\hline pre-tests & N & Mean & Std. Deviation \\
\hline Traditional classroom & 30 & 12.73 & 5.04 \\
Online classroom & 30 & 14.06 & 4.24 \\
\hline
\end{tabular}

Also, Mann-Whitney U Test was employed to investigate the observable variation in the participants' performances. The results were as follows:

Table 9. The Analysis of Pre-Tests of the Traditional Group and the Online Group, Mann-Whitney U Test

\begin{tabular}{lr}
\hline Traditional classroom- Online classroom & pre-tests \\
\hline Mann-Whitney U & 348.000 \\
Wilcoxon W & 813.000 \\
Z & -1.515 \\
Asymp. Sig. (2-tailed) & .130 \\
\hline
\end{tabular}

Note. The alpha level for the analysis was set at .05 for test of significance.

Table 9 shows that the probability level of the pre-tests of the two groups is .47 which is larger than the significance level of .05. Statistically, it follows that there is not a significant difference between pre-tests of the traditional group and the online one. In other words, the participants of the two groups had approximately similar performances on pre-tests.

\section{Comparing Post-tests of the Traditional Group and the Online Group}

To compare the post-tests of the participants of the traditional group and the online group, the raw data taken from the related tests were first examined for the assumption of normal distribution. The results were as follows: 
Table 10. The Analysis of Post-Tests of the Traditional Classroom and the Online Classroom, Test of Normality

\begin{tabular}{llll}
\hline \multirow{2}{*}{ post-tests } & \multicolumn{3}{c}{ Shapiro-Wilk } \\
\cline { 2 - 4 } & Statistic & $\mathrm{df}$ & Sig. \\
\hline Traditional classroom & .960 & 30 & .31 \\
Online classroom & .827 & 30 & .00 \\
\hline
\end{tabular}

Note. The alpha level for the analysis was set at .05 for test of significance.

As Table 10 shows, the observed values of post-tests obtained by Shapiro-Wilk are .01 and .00 , which are less than critical value at .05 level of significance and it proved that the distributions were not normal.

Table 11 presents the descriptive statistics for post-tests of the traditional group and the online one.

Table 11. The Analysis of Post-Tests of the Traditional Group and the Online Group, Descriptive Statistics

\begin{tabular}{cccc}
\hline post-tests & N & Mean & Std. Deviation \\
\hline Traditional classroom & 30 & 20.80 & 5.59 \\
Online classroom & 30 & 26.60 & 3.85 \\
\hline
\end{tabular}

In order to find out if there was any significant difference between post-tests of the traditional classroom and the online classroom, Mann-Whitney U Test was employed. The results were as follows:

Table 12. The Analysis of Post-Tests of the Traditional Group and the Online Group, Mann-Whitney U Test

\begin{tabular}{cccc}
\hline post-tests & N & Mean & Std. Deviation \\
\hline Traditional classroom & 30 & 12.73 & 5.04 \\
Online classroom & 30 & 14.06 & 4.24 \\
\hline
\end{tabular}

Note. The alpha level for the analysis was set at .05 for test of significance.

Table 12 shows that the probability level of the post-tests of the two groups is .00 which is less than the significance level of .05. Statistically, it follows that there is a significant difference between post-tests of the traditional group and the online one.

\section{Comparing the Feedback Frequencies of the Two Groups}

Regarding the participants' feedbacks, their frequencies in each of the eight sessions were accounted within the two groups. The obtained results were as follows:

Table 13. Comparing Pre-tests of the Traditional Classroom and the Online Classroom

\begin{tabular}{llll}
\hline Pre-test Group & N & Mean Rank & Sum of Ranks \\
\hline Traditional classroom & 30 & 27.10 & 813.00 \\
Online classroom & 30 & 33.902 & 1017.00 \\
Total & 60 & & \\
\hline
\end{tabular}


Table 14. Comparing Post-tests of the Traditional Classroom and the Online Classroom

\begin{tabular}{cccc}
\hline post-tests & N & Mean & Std. Deviation \\
\hline Traditional classroom & 30 & 20.80 & 5.59 \\
Online classroom & 30 & 26.60 & 3.85 \\
\hline
\end{tabular}

Regarding the distribution of the data, the related one were examined for the assumption of normal distribution. The results were as follows:

Table 15. The Distribution of the Data

\begin{tabular}{lllll}
\hline & Group & N & Mean Rank & Sum of Ranks \\
\hline Post-tests & Traditional classroom & 30 & 21.43 & 643.00 \\
& Online classroom & 30 & 39.57 & 1187.00 \\
Total & & 60 & & \\
\hline
\end{tabular}

Note. The alpha level for the analysis was set at .05 for test of significance.

Applying the normality test, it was proved that the data on the feedback frequencies of the two groups was distributed in a normal way $(\mathrm{P}>.05)$.

Table 16 presents the descriptive statistics for the feedback frequencies of the two groups, i.e. the traditional group and the online one.

Table 16. The Frequency and Percentage of Responses in Different Sessions of the Online Classroom

\begin{tabular}{|c|c|c|c|c|c|c|c|c|c|c|c|c|}
\hline & \multicolumn{2}{|c|}{ Session 1} & \multicolumn{2}{|c|}{ Session 2} & \multicolumn{2}{|c|}{ Session 3} & \multicolumn{2}{|c|}{ Session 4} & \multicolumn{2}{|c|}{ Session 5} & \multicolumn{2}{|c|}{ Total } \\
\hline & $\mathrm{N}$ & $\%$ & $\mathrm{~N}$ & $\%$ & $\mathrm{~N}$ & $\%$ & $\mathrm{~N}$ & $\%$ & $\mathrm{~N}$ & $\%$ & $\mathrm{~N}$ & $\%$ \\
\hline $\mathrm{R}(\mathrm{TS})$ & 93 & 94.89 & 133 & 97.08 & 112 & 97.39 & 104 & 97.02 & 146 & 98.64 & 588 & 97.39 \\
\hline $\mathrm{R}(\mathrm{ST})$ & 4 & 4.08 & 0 & 0 & 2 & 1.73 & 3 & 1.48 & 0 & 0 & 9 & 1.73 \\
\hline $\mathrm{R}(\mathrm{SS})$ & 1 & 1.02 & 4 & 2.91 & 1 & 0.86 & 1 & 1.48 & 2 & 1.35 & 9 & 1.86 \\
\hline Total & 98 & & 137 & & 115 & & 108 & & 148 & & 606 & \\
\hline
\end{tabular}

In order to find whether the participants' responses in the two groups were statistically different or not, the independent samples t-test was used for analyzing the related data. The results were as follows:

Table 17. The Frequency and Percentage of Responses in Different Sessions of the Traditional Classroom

\begin{tabular}{llllllllllllll}
\hline & \multicolumn{2}{c}{ Session 1 } & \multicolumn{2}{c}{ Session 2 } & \multicolumn{2}{c}{ Session 3 } & \multicolumn{2}{c}{ Session 4 } & \multicolumn{2}{c}{ Session 5 } & \multicolumn{2}{c}{ Total } \\
& $\mathrm{N}$ & $\%$ & $\mathrm{~N}$ & $\%$ & $\mathrm{~N}$ & $\%$ & $\mathrm{~N}$ & $\%$ & $\mathrm{~N}$ & $\%$ & $\mathrm{~N}$ & $\%$ \\
\hline $\mathrm{R}(\mathrm{TS})$ & 44 & 95.65 & 47 & 64 & 52 & 92.85 & 49 & 94.23 & 146 & 98.64 & 58 & 97.39 \\
$\mathrm{R}(\mathrm{ST})$ & 2 & 4.37 & 1 & 2 & 3 & 5.35 & 5 & 93.98 & 0 & 0 & 2 & 1.73 \\
$\mathrm{R}(\mathrm{SS})$ & 0 & 0 & 2 & 4 & 2 & 4.5 & 8 & 5.76 & 2 & 1.35 & 1 & 1.86 \\
\hline Total & 46 & & 50 & & 57 & & 62 & & 148 & & 61 \\
\hline
\end{tabular}

An independent-samples t-test was conducted to compare the data on the feedback frequencies of the two groups $(\mathrm{t}(14)=3.67 ; \mathrm{P}<.05)$. The magnitude of the differences in the means was very large (eta squared $=$ .49). 


\section{DISCUSSION}

The first research question in this study was: Do social networks have any effect on Iranian EFL learners' vocabulary knowledge? Regarding this research question, the pre- and post-tests of the two groups were compared. Comparing the post-tests of the two groups, it was revealed that there was a significant difference between the participants' performances after receiving the treatment program in such a way that the participants of the online classroom showed a better performance than their peers in the traditional classroom in terms of vocabulary learning (20.80 vs. 26.60).

Although the participants of the two groups improved on vocabulary learning, this improvement was more salient among the participants of the online group. Based on these findings, it can be concluded that instruction through Telegram messenger software was more effective than the instruction in the traditional class. The findings correlate with Basoglu (2010) and Yousefzadeh's (2012) who applied a mobile application and examined it in relation to vocabulary learning; and argued that the mobile application helped the learners remember the words better than non-mobile app group. The findings of the current study are also parallel to Shabani, Parseh, and Gerdabi's (2014) results who investigated the impact of using chat on vocabulary learning and reported the better performance of those participants who were instructed through chat than their peers who were instructed through traditional way. The findings also support Naseri and Khodabandeh (2019) who confirmed that social learning contexts such as Telegram make learning to be more interesting for foreign language learners, and also it allows students to have more exposure with the input or target form and interaction with their peers and teacher. The results of the research are also in line with Khodabandeh, Alian and Soleimani (2017) who believe that online classes help learners get better results than traditional classes.

Regarding the second research question, two kinds of analysis were done. The first one which was presented in the result section was counting and calculating the number and percentage of the participants' Rs and the second one is the qualitative analysis. Analyzing responses presented by the participants of the two groups, revealed that the $\mathrm{R}(\mathrm{TS})$ was the most frequent discourse element observed within both groups $(93.98 \%$ in the traditional classroom and $97.02 \%$ in the online one). Regarding this discourse element, the participants of the online classroom presented more responses to the teacher's questions than their peers in the other group (588 vs. 250) and this shows that they have been more willing to interact with their teacher and to participate in teaching-learning process. This feature cannot be seen in the traditional classroom maybe because it is a face to face interaction; and the presence of the teacher leads the students, especially the shy students, to be silent. The time limitation can affect this feature as well, because in online group all of the members can launch their answers simultaneously. Some researchers believe that there is a positive relationship between the number of the students' posts in online settings and their progress (Kay, 2006; Ramos \& Yudko, 2008).

Regarding $\mathrm{R}(\mathrm{ST})$, there were very few situations within the two groups in which students posed a problem or a question that made the teacher reply to the question. Although such situations were more frequent in the online classroom than the traditional one, this frequency was not so noticeable ( 9 vs. 8). This is also true about the $\mathrm{R}(\mathrm{SS})$ element in which students posed a problem or a question and answered to the question themselves. Our finding is inconsistent with the results of the Rashidi and Rafieerad's (2010) study who investigated the classroom discourse in EFL classrooms in Iran and showed that the IRF pattern was observed in the classes. All in all, the frequency of the R element of the IRF structure of the classroom discourse was more dominant within the online group.

The participants' Rs can also be analyzed qualitatively from other perspectives. It was observed that, in the online setting, the teacher could not have an overall and complete control over the class activities. Sometimes the teacher had to interrupt the conversation while it was deviating from the main theme, which was vocabulary learning. The learners chatted about different topics while the teacher was teaching and asking them to answer the question. For example:

Teacher: You can guess by this example: (With a loud shriek, she fled from the room).

Reza222: shout

Ghazale: I said first!!! 
M: salamm

SS: I don't know $\rightarrow 20$

Lida: scream

Teacher: now.... Make a sentence with campus.

Azita: I met best friend in the campus.

Blue:

Mina: hello

Mina: I'm here

The traditional classroom, on the other hand, was directly under the teacher's control and interrupting deviation was not obvious during the interaction. Therefore, it can be said that probably the setting affects the teaching method that it can affect the way of presenting the method. Van Lier (1996) believed that IRF pattern is effective in learning foreign languages since the regular pattern does not allow the discourse to be deviated from the main theme. He said that teacher's control in classroom improves students' achievements. But the results of this study showed the reverse. While in the online setting the teacher's control was less and the conversation was not relevant to the topic of the study most of the time, the online group showed better performance in learning.

In online setting, the participants had a collaborative learning. Every time the teacher asked them to do something, they did it collaboratively. For instance, when they guessed the meaning of a new word, they commented about their guesses, or when they were asking to make a code for memorizing the words. This is in accordance with Vygotsky (1986).

In the traditional classroom, the IRF pattern was established and the teacher's initiation and the students' responses according to the structure could be seen in the interaction:

Teacher: What's the meaning of shriek?

Student: I don't know.

Teacher: Can you guess by this example, (With a loud shriek, she fled from the room).

Student: loud voice?

But in the online setting, this pattern is disrupted;

Teacher: The first word is shriek.

Reza: hello

Asal: :) :; :)

Teacher: What's the meaning of shriek?

Teacher: You can guess by this example: (With a loud shriek, she fled from the room).

Reza222: shout

Sara: cry

Ghazale: voice???

Ghazale: I said first!!!

M: salamm

SS:I don'tknow $@$

Lida: scream

A concept called 'adjacency pairs' exists in face to face interaction, which means that the utterances are near to each other (Wang, Newlin \& Tucker, 2001). The below example from a part of interaction of online class shows it: 
Teacher: What's the meaning of shriek? (Teachers gives an example)

Student: voice??

Student: loud voice?

Student: shouting

Teacher: bravo

Teacher: Make a sentence with shriek, please.

Student: I don't like to shriek when I feel danger

Student: I heard a loud shriek when I was walking in the street

In online chat, this does not exist; and according to Garcia and Jacobs (1999), something that is called 'disrupted adjacency' happens. In all of the sessions some unrelated comments were observed which is one of the features of online classes.

Teacher: now.... Make a sentence with campus.

Azita: I met best friend in the campus.

Blue:

Mina:hello

Mina: I'm here

In the online group, the participants liked responding to each other's comments. Sometimes they confirmed each other, sometimes they joked, and so on. This feature was not dominant in the traditional classroom. When the members of the online group interacted with each other, they couldn't see each other. So, they could not see each other's reactions. In face to face interaction, the speakers could see others' gestures or hand or eye movements or they could express themselves better by using these movements. For example, they could make faces if they did not understand each other. In online setting these features can be expressed by using emoticons.

In the online setting the participants supported and helped each other in learning. For instance, when one member made a new code for the new vocabulary, the other participants expressed their ideas or confirmed or rejected the code. In some occasions they helped each other in guessing words. All in all, the collaborative learning was more obvious among the online group. This collaborative learning can be one of the elements of success among the online group. This can be in accordance with Vygotsky (1978) who believed that children learn better in social environment than individually.

Online chat has some features that make online setting a totally different context from traditional one. In the first setting, there were some bases for taking the turns, which Cameron (2001) talks about and believes that the person who speaks chooses who will be the next speaker or he himself continues. In online chats, the participants continued to send their posts without paying attention to turns. Responses to questions or comments were not according to turns, as well. An initiating response can produce many responses that may or may not be related to the topic under discussion.

\section{CONCLUSION}

The purpose of this study was to examine the participants' responses in two different modes of learning (virtual and traditional classrooms) and to see whether there were any differences in their responses. Moreover, this study attempted to compare two different modes of learning vocabulary (traditional and online group) and to examine the effectiveness of these two modes in vocabulary acquisition. The finding of this study shows that the number of responses and the participants' interaction during teaching-learning process were more among the participants of the online classroom than their peers in the other group, i.e. traditional classroom. This study also showed some features of the two classes (traditional and online) which were different in these two settings, like turn taking, using stickers, answering other's comments, adjacency pairs, and the number of comments. Some of the features like the number of comments, unrelated posts, answering others' comments, the stickers, and humor were more dominated in the online classroom. 
Comparing pre- and post-tests of the participants of the traditional classroom, it was revealed that there was a significant difference between their performance before and after the treatment program. This was also the case for the participants of the other group, i.e. the online classroom. However, this effectiveness was more salient among the participants of the online classroom. In other words, teaching and learning vocabulary through keyword method may lead to better and more vocabulary learning in virtual or online classes than traditional ones.

\title{
Suggestions for Further Studies
}

The participants of this study were at intermediate level of proficiency. It is possible to conduct such a research with participants at other levels of English proficiency that can be taken into account in future studies. Future studies can focus on the students' feedback in virtual classes especially in story telling courses. Also learners' feedback in traditional and online classes can be compared.

\section{Implications of the Study}

This study may have some implications for teachers, and learners. It may help teachers to determine proper procedures and techniques for developing language learners' word learning-strategies and thereby they can become more proficient at other language skills. Regarding the way of presenting the treatment program, the findings revealed the better performance or more effective vocabulary learning of those students who received the intended treatment through telegram messenger software than those students who received it through traditional way, i.e. class attending instruction. This can encourage teachers to enjoy the benefits of new opportunities which have been provided by technology in teaching-learning process.

\section{Limitations and Delimitations of the Study}

One limitation encountered during conducting the research was that some students did not have access to Internet and a smart phone. In order to overcome this problem, it was attempted to select those students who had the requirements or those who were able to get them. The low speed of Internet was another limitation of the study which did not allow the participants to download and upload audio messages. Therefore, they preferred to participate in the teaching-learning process by sending text messages. Limited duration of the study was also another limitation and this was because of the nature of Payame Noor university system.

\section{BIODATA and CONTACT ADDRESSES of AUTHORS}

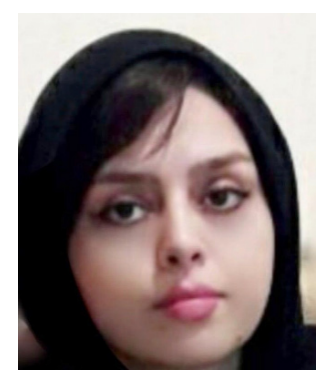

Marjan BANAFSHI holds a BA in English translation and an MA in English teaching from Payment Noor University. She is an English instructor and has been teaching English for 8 years at institutes and one year in Payame Noor University. Her academic areas of interests are distance learning, learning through social media and online education

\author{
Marjan BANAFSHI \\ Department of Linguistics and Foreign Languages \\ Faculty of Humanities \\ Address: Payame Noor University, 19395-3697, Iran \\ Phone: +989052534785 \\ E-mail: banafshee1366@yahoo.com
}


Farzaneh KHODABANDEH is an assistant professor at Payame Noor University. She gained her Ph.D. in TEFL in 2013. She is the author of four academic textbooks and has presented more than 20 international and national conferences and published papers in international and national indexes. She has a 20-year experience of teaching English; 15 years of teaching and research in distance education. She is the advisor and reader to over 30 post-graduate theses. Her academic interest areas are social network analysis, open and distance learning, CALL, MALL, e-learning, and discourse studies.

Farzaneh KHODABANDEH

Department of Linguistics and Foreign Languages

Faculty of Humanities

Address: Payame Noor University, 19395-3697, Iran

Phone: (+)98-9131043792

E-mail: Farzaneh.khodabandeh@gmail.com

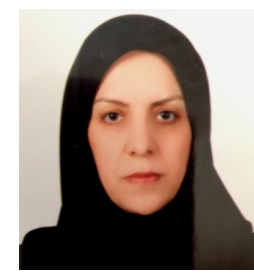

Fatemeh HEMMATI is an associate professor at Payame Noor University, Tehran, Iran. She gained her Ph.D.in TEFL from University of Essex, England. She has published papers in international and national Journals. Her academic interest areas are classroom discourse analysis, writing skill and pragmatics.

Fatemeh HEMMATI

Department of Linguistics and Foreign Languages

Faculty of Humanities

Address: Payame Noor University, 19395-3697, Iran

Phone No: (+)989123789248

E-mail: hematitefl@gmail.com

\section{REFERENCES}

Allwright, R. L. (1980). Turns, topics, and tasks: Patterns of participation in language learning and teaching. In D. Larsen-Freeman (Ed.), Discourse analysis in second language research (pp.165-187). Rowley, MA: Newbury House.

Allwright, D., \& Bailey, D. (1991). Focus on the language classroom. An introduction To classroom research for language teachers. Cambridge: Cambridge University Press.

Atkinson, R. C. (1975). Mnemotechnic in second-language learning. American Psychologist,30, 821-828.

Atkinson, R. C., and Raugh, M. R. (1975). An application of the mnemonic keyword to the acquisition of Russian vocabulary. Journal of Experimental Psychology: Human Learning and Memory, 104, 126133.

Avila, E. \& Sadoski, M. (2006). Exploring new applications of the keyword method to acquire English vocabulary. Language Learning, 46 (3), 379-395.

Aydin,S. (2014). Foreign language learners' interactions with their teachers on Facebook. System,42, 155163.

Badri,A.(2015). The effects of Technology on Idioms: with a Focus on Law Terms (A Study in Payame Noor University, Tehran, Iran). International journal of educational investigations,2(8),43-53.

Basoglu, E. B. (2010). A comparison of undergraduate students' English vocabulary learning: Using mobile phones and flashcards. Educational Technology, 9(3), 1-7.

Behnam,B., \&Pouriran, Y. (2009). Classroom Discourse: Analyzing Teacher/Learner Interactions in Iranian EFL Task- Based Classrooms. Porta linguarum, 12,117-132. 
Berkeley, S. L., Mastropieri, M. A., Marshak, L., \& Scruggs, T. E., (2010). Mnemonic Strategies: EvidenceBased Practice and Practice-Based Evidence. Intervention in School and Clinic, 46(2), 79-86.

Black, S.D., Levin, J.A. \& Mehan, H. (1983). Real and non-real time interaction: Unraveling multiple threads of discourse. Discourse Processes 6, 59-75.

Cameron. D. (2001). Working with Spoken Discourse. London: Sage Publications.

Candela, A. (1999). Students' power in classroom discourse. Linguistics and Education, 10 (2), 139-163.

Carpenter, S., \& Olson, K. (2012). Are pictures good for learning new vocabulary in a foreign language? Only if you think they are not. Journal of Experimental Psychology: Learning, Memory, and Cognition, 38(1), 92-101.

Cazden, C.B. (2001). Classroom discourse. The language of teaching and learning. Portsmouth, NH: Heinemann.

Castro, M.C..(2006). Let's Chat: An analysis of some discourse features of synchronous chat. Journal of English studies and comparative literature, 9(1), 77-94.

Chun, D., \& Plass, J. (1996). Effects of Multimedia Annotations on Vocabulary Acquisition. The Modern Language Journal, 80 (2), 183-198

Crystal, D. (2001). Language and the Internet, Cambridge University Press, Cambridge.

Cullen, R. (1998). Teacher talk and the classroom context. ELT Journal, 52, 179-187.

Edwards, A.D., \& Westgate, D.P.G. (1994). Investigating classroom talk. London; Washington D.C.: Falmer Press.

Farahian, M., \& Rezaee, M. )2012). A case study of an EFL teacher's type of questions: an investigation into classroom interaction. Procedia - Social and Behavioral Sciences, 47, 161-167.

Ellis, R. (1994). The study of second language acquisition. Oxford: Oxford University Press.

Firat, M., \& Serpil, H. (2017). Comparing the internet usage of pre-service language teachers with teachers of other subjects: Distance learning vs. on-campus learning. Profile Issues in Teachers Professional Development, 19(1), 55-72.

Gallini, J.K., \& Barron, D. (2002). Participants' perceptions of web-infused environments: A survey of teaching beliefs, learning approaches, and communication. Journal of Research on Technology in Education, 34(2), 139-156.

Garcia, A.C. \& Jacobs, J.B. (1999). The eyes of the beholder: Understanding the turn-taking system in quasi-synchronous computer-mediated communication. Research on Language and Social Interaction,32(4), 337-367.

Gere, C. (2002). Digital culture. London: Reaktion Books Ltd.

Gibson,W.J.(2014). Sequential order in multimodal discourse: Talk and text in online educational interaction. Discourse \& Communication, 8(1), 63-83.

Greenhow, C., (2011), Online social networks and learning. On the Horizon, 19 (1), 4-12.

Harmer, J. (1998). The practice of English language teaching. London: Longman.

Heidari, J., Khodabandeh, F., \& Soleimani, H. (2018). A comparative analysis of face to face instruction vs. Telegram mobile instruction in terms of narrative writing. JALT CALL Journal, 14(2), 143-156.

Hell, J. G. V. \& Mahn, A. C. (1997). Keyword Mnemonic Versus Rote Rehearsal: Learning Concrete and Abstract Foreign Words by Experienced and Inexperienced Learners. Language Learning, 47(3), 507-546.

Karayan, S., \& Crowe, J. (1997). Student perspectives of electronic discussion groups. THE Journal: Technological Horizons in Education, 24(9), 69-71. 
Kay, R. H. (2006). Developing a comprehensive metric for assessing discussion board effectiveness. British Journal of Educational Technology, 37(5), 761-783.

Kearsley, G. (2000). Online education: Learning and Teaching in Cyberspace. Belmont, CA: Wadsworth.

Khabiri, M, \& Khatibi, M. B. (2013). Mobile-assisted language learning: Practices among Iranian EFL learners. European Online Journal of Natural and Social Sciences, 2(2), 176-190.

Khodabandeh, F. (2018). The impact of storytelling techniques through virtual instruction on English students' speaking ability. Teaching English with Technology, 18(1), 24-36.

Khodabandeh, F., Alian, J. \& Soleimani, H. (2017). The effect of mall-based tasks on EFL learners' grammar learning. Teaching English with Technology, 17(2), 29-41.

Kolokytha, E., Loutrouki, S., Valsamidis,S., \& Florou,G. (2015).Social media networks as a learning tool. Procedia Economics and Finance, 19,287-295.

Liu, J. \&, Le, T. (2012). A case study on College English classroom discourse. International Journal of Innovative Interdisciplinary Research. 2, 1-9.

Liu, Y. (2008). Teacher-student talk in Singapore Chinese language classrooms: A case study of initiation/ response/follow up (IRF). Asia Pacific Journal of Education, 28, 87-102.

Lyle, S. (2008). Dialogic teaching: Discussing theoretical contexts and reviewing evidence from classroom practice. Language and Education: An International Journal, 22(3), 222-240.

McConnell, D. (2000). Implementing computer supported cooperative learning. London: Kogan Page Limited.

Markee, N. (2000). Conversation analysis. Mahwah, NJ: Lawrence Erlbaum.

McHoul, A. (1978). The organization of turns at formal talk in the classroom. Language in Society, 7(2), $183-213$.

Mishler, Elliot G. (1975). Studies in dialogue and discourse: II. Types of discourse initiated by and sustained through questioning. Journal of Psycholinguistic Research 4(2). 99-121.

Miyazoe,T \& Anderson, T.(2010). Learning outcomes and students' perceptions of online writing: Simultaneous implementation of a forum, blog, and wiki in an EFL blended learning setting. System,38 (3), 515 .

Molinar, L., Mameli, C., \& Gnisci, A. (2013). A sequential analysis of classroom discourse in Italian primary schools: The many faces of the IRF pattern. British Journal of Educational Psychology, 83, 414-430.

Mondada, L. (2007). Multimodal resources for turn-taking: Pointing and the emergence of possible next speakers. Discourse Studies, 9(2): 194-225.

Myhill, D. \& Dunkin, F. (2005). Questioning learning. Language and Education 19(5),415-427

Naseri, E., Khodabandeh, F. (2019). Comparing the impact of audio-visual input enhancement on collocation learning in traditional and mobile learning contexts. Applied Research on English Language, 8(3), 383-422. doi: 10.22108/are.2019.115716.1434

Nassaji, H. \&. Wells, G. (2000). What's the use of "triadic dialogue"? An investigation of teacher-student interaction. Applied Linguistics 21(3), 376-406

Nilsen, M., \& Mäkitalo, A. (2010). Towards a conversational culture? How participants establish strategies for coordinating chat postings in the context of in-service training. Discourse Studies 12(1), 90105.

Nunan, D. (1991). Language teaching methodology: A textbook for teachers. New Jersey: Prentice Hall. O'Connor, C., \& Michaels, S. (2007). When dialogue is 'dialogic'. Human Development, 50,275285.

Quinn, C.N., Mehan, H., Levitt, J.A. \& Black, S.D. (1983). Real education in non-real time: The use of electronic message systems for instruction. Instructional Science, 11, 313-327. 
Rains, S. A. (2007). The impact of anonymity on perceptions of source credibility and influence in computermediated group communication: A test of two competing hypotheses. Communication Research, 34,955-970.

Ramos, C., \& Yudko, E. (2008). "Hits" (not "discussion posts") predict student success in online courses: A double cross-validation study. Computers and Education, 50(4), 1174-1182. doi: 10.1016/j. compedu.2006.11.003

Rampton, B. (2002). Ritual and foreign language practices at school. Language in Society, 31(4), 491-525.

Rashidi, N. \& Rafieerad, M. (2010). Analyzing patterns of Classroom Interaction in EFL Classrooms in Iran. The journal of Asia TEFL,7(3), 93-120.

Rithika, M., \& Selvaraj, S. (2013). Impact of social media on student's academic performance. International Journal of Logistics \& Supply Chain Management Perspectives, 2(4), 636-640.

Rodriguez, M. \& Sadoski, M. (2000). Effects of rote, context, keyword, and context/keyword methods on retention of vocabulary in EFL classrooms. Language Learning, 50 (2).385-412.

Rymes, B. (2009). Classroom discourse analysis: A tool for critical reflection. Cresskill, NJ: Hampton Press.

Sachs, H., Schegloff, E.A. \& Jefferson, G. (1974). "A Simplest Systematic for the organization of turn-taking in Conversation", Language, 50 (4), 696-735.

Sagarra, N., \& Alba, M. (2006). The key is in the keyword: L2 vocabulary learning methods with beginning learners of Spanish. The Modern Language Journal, 90(2), 228-243

Seedhouse, P. (1996) Classroom interaction: possibilities and impossibilities. ELT Journal, 50(1), 16-24.

Shabani,M.B., Parseh,F., \& Gerdabi, A. (2014). The impact of chat on the vocabulary retention of Iranian EFL learners. International Journal of Language Learning and Applied Linguistics World5,3,286-305.

Shapiro, A. M. \& Waters, D. L (2005). An investigation of the cognitive processes underlying the keyword method of foreign vocabulary learning. Language Learning, 9 (2), 129-146.

Sinclair, J. \& Coulthard, M. (1975). Towards an analysis of discourse: The English used by teachers and pupils. London: Oxford University Press.

Smith, D., \& Hardaker, G. (2000). e-Learning innovation through the implementation of an Internet supported learning environment. Educational Technology and Society, 3, 1-16.

Smith,H \& Higginsb,S. (2006). Opening classroom interaction: the importance of feedback. Cambridge journal of education,36 (4), 485-502.

Song,L. \& McNary, S.W. ( 2011). Understanding Students' Online Interaction: Analysis of Discussion Board Postings. Journal of Interactive Online Learning, 10(1),1-14.

Stanciu,A., Mihai,F., \& Aleca,O. (2012).Social networking as an alternative environment for education. Accounting and Management Information Systems, 11(1), 56-75.

Sunderland, J. (2001). Student initiation, teacher response, student follow-up: towards an appreciation of student-initiated IRFs in the language classroom. Retrieved from: http://www.ling.lancs.ac.uk/ groups/crile/docs/crile55sunderl.pdf

Swan, K. (2002). Building learning communities in online courses: The importance of interaction. Education, Communication \& Information, 2(1), 23-49.

Thornborrow, J. (2002). Power talk. Language and interaction in institutional discourse. Harlow: Longman.

Trentin, G. (2000). The quality-interactivity relationship in distance education. Educational Technology, 40(1), 17-27.

Tsui, A. (1995). Introducing classroom interaction. London: Penguin.

Underwood, J. (1989). HyperCard and interactive video. CALICO, 6, 7-20. 
van Lier, L. 1996. Interaction in the language curriculum: awareness, autonomy and authenticity. London: Longman.

Vygotsky LS (1978) Mind in society: the development of higher psychological processes. Harvard University Press, Cambridge.

Vygotsky LS (1986) Thought and language. The MIT Press, Cambridge

Walsh, S. (2006). Investigating classroom discourse. London: Routledge.

Wang, A.Y, Newlin, Michael.H., \& Tucker,T.L. (2001). A Discourse Analysis of Online Classroom Chats: Predictors of Cyber-Student Performance. Teaching of psychology,28(3), 222-226.

Wang, Y.C. (2014). Using wikis to facilitate interaction and collaboration among EFL learners: A social constructivist approach to language teaching. System, 42, 383-390.

Wanger, E. D., \& Wilson, P. (2005). Disconnected: why learning professional need to care about mobile learning. American Society for Training and Development, 59(12), 40-43.

Wells, G. (1999). Dialogic inquiry: Toward a sociocultural practice and theory of education. Cambridge: Cambridge University Press.

Wyra, M., Lawson, M. J., \& Hungi, N. (2007). The mnemonic keyword method: The effects of bidirectional retrieval training and of ability to image on foreign language vocabulary recall. Learning and Instruction, 17, 360-371.

Yousefzadeh, M. (2012). Mobile- based learning vs. paper-based learning and collocation words learning. Journal of Educational and Instructional Studies, 2(3), 216-220.

Zeng,G. \& Shigenobu, T. (2009). Text-based peer-peer collaborative dialogue in a computer-mediated learning environment in the EFL context. System, 37(1). 434-446. 